\title{
Glucose 6-phosphate dehydrogenase deficiency and cystic fibrosis
}

\author{
P. J. Congdon \\ M.B., M.R.C.P. \\ R. K. Aggarwal \\ M.B., Ch.B.
}

J. M. LITTLEWOOD

H. SHAPIRO

M.B., Ch.B.

Department of Paediatrics, St James' University Hospital, Beckett Street, Leeds LS9 7TF

\begin{abstract}
Summary
A child born to Pakistani parents is described. He had both cystic fibrosis and G-6PD-deficiency. So far as can be ascertained, the occurrence of both these conditions in the same individual has not previously been reported.
\end{abstract}

\section{Introduction}

Cystic fibrosis (CF) occurs in approximately 1 in 2000 Caucasian births, but is rare in other races (di Sant'Agnese and Davis, 1976). In Negroes the incidence is 1 in 17000 (di Sant'Agnese and Davis, 1976), while cases from the Indian sub-continent are even rarer (Reddy et al., 1969). Glucose 6-phosphate dehydrogenase (G-6PD) deficiency, a sex-linked disorder causing haemolysis primarily in males, occurs mainly in people from Africa, China, the Mediterranean and parts of Asia (Luzzatto, 1975). Although there have been reports of CF in association with $\alpha_{1}$-antitrypsin deficiency, cri-du-chat syndrome, Kartagener's syndrome, Wiskott-Aldrich syndrome and Down's syndrome (di Sant'Agnese and Davis, 1976), so far as the authors know, the occurrence of both CF and G-6PD-deficiency in the same individual has not been previously reported.

\section{Case report}

A $2.85 \mathrm{~kg}$ infant, born to non-consanguineous Pakistani parents, was found on routine screening for cystic fibrosis to have a positive BM meconium test (Prosser et al., 1974). Faecal chymotrypsin levels (Robinson, Smith and Elliott, 1975) in the first week were between 19-37 $\mu \mathrm{g} / \mathrm{g}$ (normal $100 \mu \mathrm{g} / \mathrm{g}$ ). Sweat electrolytes on the sixth day were sodium 165 , chloride $180 \mathrm{mmol} / 1$ (64 $\mathrm{mg}$ sweat). Despite a satisfactory intake, the weight at the age of 3 weeks had fallen to $2 \cdot 75 \mathrm{~kg}$. Investigations at this stage were: Hb $11.1 \mathrm{~g} / \mathrm{dl}$; WBC $\left(9.6 \times 10^{9} / 1\right)$; chest X-ray was normal; repeat sweat test sodium 88, chloride $97 \mathrm{mmol} / 1$ (192 $\mathrm{mg}$ sweat). In view of the clinical picture, 2 abnormal sweat tests, and the low chymotrypsin levels, a diagnos of CF was made and standard treatment with pancreatic replacements (Cotazyme), oral cloxacillin and physiotherapy was commenced.

At the age of 5 weeks, increasing pallor was noted but the child was not jaundiced. Investigations at this stage revealed a $\mathrm{Hb}$ of $5.6 \mathrm{~g} / \mathrm{dl}$; WBC $8.3 \times 10^{\%} / 1$; platelets $355 \times 10^{9} / 1$ reticulocytes $17 \%$; serum iron $15 \mathrm{mmol} / 1$ (normal 14-31 mmol/l) and serum folate $10.5 \mu \mathrm{g} / \mathrm{l}$ (normal 2.5-20 $\mu \mathrm{g} / \mathrm{l}$ ), vitamin E $420 \mathrm{mg} / \mathrm{dl}$ (normal 520-1140 mg/dl). The dye decolorization screening test for G-6PD-deficiency was positive and subsequently no G-6PD activity was detected (Glock and McLean, 1953). He was transfused with fresh blood and subsequent progress has been satisfactory.

He continues to thrive on pancreatic supplement but no antibiotics. There has been no further evidence of haemolysis, and haemoglobin levels have remained between $9.5-11.5 \mathrm{~g} / \mathrm{dl}$. The dye decolorization time in the mother was $>7 \mathrm{hr}$, no G-6PD activity was detected in her red cells. The father has not been investigated.

\section{Discussion}

There is little doubt that this infant has both CF and G-6PD deficiency, a hitherto unreported association. The fall in $\mathrm{Hb}$ associated with reticulocytosis at the age of 5 weeks suggested haemolysis. Numerous drugs, including acetyl salicylic acid, sulphonamides, and even a local antiseptic applied to the umbilical stump, can precipitate acute haemolysis in G-6PD deficiency (Valaes, 1969). The only drugs this infant received were Cotazyme and cloxacillin, but penicillin and its derivatives are not associated with haemolysis in G-6PD deficiency, and Cotazyme 
has been continued with no further evidence of haemolysis. Dolan (1976) reported 5 children less than 4 months old with CF, all with evidence of a haemolytic anaemia probably due to vitamin $\mathrm{E}$ deficiency. The present infant was also vitamin Edeficient and both this and G-6DP deficiency can result in red cell membrane injury with consequent haemolysis (di Sant'Agnese and Davis, 1976; Valaes, 1969). Although infections are associated with increased haemolysis, there was no clinical or radiological evidence of pulmonary infection.

While subsequent progress has been satisfactory, the interest of these 2 conditions occurring together is the possible role that G-6PD deficiency may have in the control of pulmonary infections. Although it has been suggested that patients with G-6PD deficiency are more prone to infections (Schlegel and Bellanti, 1969), immunological studies in CF have not shown any definite underlying immunological defect (di Sant'Agnese and Davis, 1976). In contrast to Negroes with G-6PD deficiency, nonNegroes with this disorder have more severely affected erythrocytes and also decreased enzymatic activity in their leucocytes (Luzzatto, 1975). An increased susceptibility to infection as a result of impaired bactericidal function of these leucocytes has been observed in some patients (Gray et al., 1973; Cooper et al., 1972). Of particular relevance to this case is the finding by Cooper et al. (1972) of an adult with G-6PD-deficiency whose leucocytes had an inability to kill Escherichia coli and Staphylococcus aureus. It is possible that respiratory infections with subsequent pulmonary damage will be more marked in this infant because of the impaired leucocyte function. Fortunately, most of the antibacterial agents which will be needed to control pulmonary infections are unlikely to precipitate haemolysis (Valaes, 1969).

\section{References}

Cooper, M.R., de Chatelet, L.R., McCale, C.E., Lavif M.F., SPURR, C.L. \& BaCHner, R.L. (1972) Comple E্ট: deficiency of leukocyte glucose-6-phosphate dehydrogenase with defective bactericidal activity. Journal of Clinic Investigation, 51, 976.

Di SANT'Agnese, P.A. \& Davis, P.B. (1976) Research $\overparen{f}$ cystic fibrosis, New England Journal of Medicine, 295, 48

Dolan, T.F. (1976) Hemolytic anemia and edema as initial signs in infants with cystic fibrosis. Clinical Pediatrics, 15 597.

Glock, G.E. \& McLean, P. (1953) Further studies on the properties and assay of glucose-6-phosphate dehydrogenas +6-phosphogluconate dehydrogenase of rat liver. $B i$. chemical Journal, 55, 400.

Gray, G.R., Klebanoff, S.J., Stamatoyannopoulos, $Q_{\text {T }}$ Austin, T., Naiman, S.C., Yoshida, A., Kliman, M.R. Robinson, G.C.F. (1973) Neutrophil dysfunction, chronic granulomatous disease, and non-spherocytic haemolytice anaemia caused by complete deficiency of glucose- 80 phosphate dehydrogenase. Lancet, ii, 530.

LuzzatTo, L. (1975) Inherited haemolytic states: glucose-6. phosphate dehydrogenase deficiency. Clinics in Haemato$\log y, 4,83$.

Prosser, R., OWen, H., Bull, F., Parry, B., Smerkinich, J., Goddwil, H.A. \& Dathan, J. (1974) Screening cystic fibrosis by examination of meconium. Archivg $\mathscr{R}$ Disease in Childhood, 49, 597.

RedDY, C.R.R.M., Devi, C.S., ANeES, A.M., Morthy, 遍: \& REDDY, G.E. (1969) Cystic fibrosis of the pancreas India. Journal of Pediatrics, 75, 522.

Robinson, P.G., Smith, P.A. \& Elliott, R.B. (1975) simple method for the quantitative determination of sto trypsin and chymotrypsin. Clinica chimica acta, 62, 225ळ

Schlegel, R.J. \& Bellanti, J.A. (1969) Increased suscept bility of males to infection. Lancet, ii, 826.

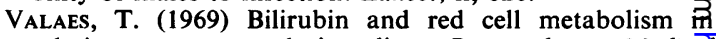
relation to neonatal jaundice. Postgraduate Medic Journal, 45, 86. 